follows a list of references and addenda to the various chapters which brings the literature survey up to the end of 1952. The completeness of this section is an outstanding feature.

It is remarkable how well the authors have succeeded, in a book of ordinary dimensions, in dealing so adequately with such a wide subject. The emphasis has rightly been on the newer methods, but important aspects of the older have not been ignored. There are many valuable features. For example, more than ninety tables of $R_{F}$ values are given, which cover many hundreds of substances. There are many tables which give useful information at a glance, and the book is generously illustrated with diagrams and photographs of apparatus, chromatograms, elution curves, and so on. It is an achievement of the book that many of the methods are sufficiently well described to enable one to carry them out in the laboratory without having to delve through a mountain of literature beforehand. Division of the text into many subsections has made for attractiveness in presentation. A word of tribute, too, must be paid to Dr. A. T. James, who translated part of the book from the original French into good English.

In a book which provides so much information, one feels diffident in suggesting that a little more could have been given in one or two places. There might, for example, have been provided representative chemical formulæ for all the numerous classes of organic compounds-for who but the finalyear chemistry honours student remembers them all ? Perhaps a more detailed explanation could have been given of how the identification of the products of partial hydrolysis of complex substances helps to provide a picture of the whole structure, and more about how some of the reagents (ninhydrin, for example) used in paper chromatography react with the substances for which they are used. There might be some justification, in view of the correspondence in Nature (which is cited), to have included in the historical section some account of the contributions to chromatography made by British contemporaries of Tswett. It would have been helpful if the references, which are arranged in alphabetical order, were each followed by the page number in the text.

These are, however, minor eriticisms. The authors and publishers are to be congratulated on the production of an attractive book of outstanding im. portance. It should be in the hands of those who use chromatographic methods, those who expect to use them and those who ought to use them-that is, every chemist and biochemist.

\section{PHYTOGEOGRAPHICAL WRITINGS OF SIR JOSEPH HOOKER}

\section{Pioneer Plant Geography}

The Phytogeographical Researches of Sir Joseph Dalton Hooker. By Dr. W. B. Turrill. (Lotsya-A Biological Miscellany-Volume 4.) Pp. xii $+267+$ 21 plates. (The Hague: Martinus Nijhoff, 1953.) 19 guilders.

D ARELY can Fortune have showered so many of her favours on a botanist as she did on Sir Joseph Dalton Hooker, and seldom can there have been a botanist more fitted to make the most of them. The son of Sir William Jackson Hooker, he was born in the botanical purple, and his father's distinguished career afforded him quite exceptional opportunities for his own scientific work. But his time was also propitious; born in 1817 and living until 1911, his life almost exaetly spanned the longest and most complete period of tranquillity, freedom from distraction, and material prosperity that Great Britain has ever known, while his birth made him of such an age that he rode the rising tide of scientific progress at its flood and became, almost inescapably, a foundation member of the new biology. But, above all, Fortune endowed him with qualities of mind and character which enabled him to profit from all these circumstances. Fate offered him a giant's place, and he was big enough to fill it.

As with pioneers in many other walks of life, it fell to Joseph Hooker to say, for the first time, many fundamentally important things about his subject. Nowhere is this more obvious than in his phytogeographical writings, and Dr. W. B. Turrill has therefore done a very worth-while service in reminding us again of their more important passages. It is all too easy to think of such early work only in the idiom of to-day and to forget the part it has played in forging the ideas which now we think of as our own.

Some readers will doubtless be most interested in those extracts which reveal Hooker's attitude towards Darwinism and his gradual, though not very convincing, assimilation of it; but it is with plant geography that Dr. Turrill's book is almost wholly concerned. One's first feeling here is astonishment that so much was known so early in Hooker's career, and some slight chagrin that the advance since then has not been greater; but this is, for many reasons, rather unjust, although the fact seems to remain that only in the realm of palæogeography have we really passed beyond Hooker's comprehension. Many of the problems which troubled him are the problems which still perplex us, very notable among them being that of the way in which the oceanic islands and more isolated mountains of the world have become populated. These are still, as they were in his day, among the most erucial issues of plant geography.

"Pioneer Plant Geography" in the main takes the form of a series of chapters arranged in a formal geographical sequence, each consisting of long extracts from the relevant writings of Hooker, and a summary, by Dr. Turrill, of subsequent work on the same matters. The book is pleasantly produced, and there is a useful bibliography. In total it contains a great deal of information, some of it not easily come by elsewhere, and will certainly become an important source book for plant-geographers. At the same time, it does not conceal some of the exceptional difficulties inherent in a book of this sort. Of these only the author himself can be fully aware, and one hesitates, therefore, to comment on his procedure; but many will, perhaps, feel that Dr. Turrill's decision to abandon the chronological approach was an unfortunate one, since it not only threw away the most potent source of continuity in the narrative, but also deprived the reader of any opportunity of following the development of Hooker's personality and science. In consequence of this the book is somewhat lifeless, which, bearing in mind its subject, is a pity. It is also a little unfortunate that, owing to this geographical arrangement of the book, it first presents the least satisfactory of Hooker's geographical writings and leaves the consideration of his most classic (and earliest) memoirs to the end.
RoNALD GOOD 